\title{
Factors Influencing the Adoption of Small-scale Biogas Digesters in Developing Countries - Empirical Evidence from Vietnam
}

\author{
Ngo Thi Thanh Truc ${ }^{1}$, Tran Sy Nam², Nguyen Vo Chau Ngan ${ }^{3}$, Jan Bentzen ${ }^{4}$ \\ ${ }^{1}$ College of Economics, Can Tho University, Campus II, 3/2 Street, Ninh Kieu District, Can Tho City, Viet Nam \\ ${ }^{2}$ College of Environment and Natural Resources, Can Tho University, Campus II, 3/2 Street, Ninh Kieu District, \\ Can Tho City, Viet Nam \\ ${ }^{3}$ College of Environment and Natural Resources, Can Tho University, Campus II, 3/2 Street, Ninh Kieu District, \\ Can Tho City, Viet Nam \\ ${ }^{4}$ Tuborg Research Centre for Globalisation and Firms, Department of Economics and Business Economics, \\ Aarhus University, Fuglesangs Allé 4, DK-8210 Aarhus V, Denmark \\ Correspondence: Jan Bentzen, Tuborg Research Centre for Globalisation and Firms, Department of Economics \\ and Business Economics, Aarhus University, Fuglesangs Allé 4, DK-8210 Aarhus V, Denmark. \\ E-mail: jb@econ.au.dk
}

Received: November 25, 2016

Accepted: December 16, 2016 Online Published: December 23, 2016

doi:10.5539/ibr.v10n2p1

\author{
URL: http://dx.doi.org/10.5539/ibr.v10n2p1
}

\begin{abstract}
The use of small-scale biogas digesters among farmers and households in rural areas of developing countries is a well-known technology. The potential for biogas in these areas is probably much larger than presently exploited and therefore more knowledge on factors that may further the use of biogas is needed. The present study draws on data from two extensive surveys in the Mekong Delta with questionnaires of one hundred and two hundred respondents, respectively, and data collected from personal interviews in all cases. The empirical evidence shows that the technology is well known and if the purpose is to expand the use of biogas, financial instruments (like subsidies) are the most important to rely on. High investment costs are important for the biogas investment decision and subsequently information on the economic benefits of cheap biogas is an important topic to address.
\end{abstract}

Keywords: small-scale biogas, developing countries, Mekong Delta, barriers for biogas adoption, survey data, logit model

\section{Introduction}

In many developing countries the conversion of animal dung into biogas has been recognized for a long time as a cheap and stable source of energy supply, e.g. in South East Asia where the warm climate is favorable for biogas production. In these countries the biogas is most often used for cooking purposes and by displacing fossil fuels it can be both cost saving and more environmentally friendly than the alternative energy sources. From India to China millions of small farmers and households use simple versions of the biogas digester technology and that will fulfil most of the household energy needs, like cooking and lighting purposes, Nautiyal et al. (2015) and Jiang et al. (2011). Today, the international environmental agenda also for developing countries is to take part in reduction of carbon emissions by increasingly relying on sustainable energy sources and thus reducing the usage of fossil fuels. Biogas produced from local resources as pig and cow manure is nicely fitting with such purposes, and additional to being cost-effective and climate-friendly it can have positive health effects, e.g. when replacing firewood in indoor kitchens. The potential for biogas is considered huge in many developing countries but there seems to be various barriers for the further diffusion of biogas technologies, see e.g. Schmidt and Dabur (2014) and Christiansen and Heltberg (2013). Thus, the locally based biogas with a digester using animal dung and serving one or a few households is a sustainable technology, saving both money and fossil fuels like LPG or coal, and it may contribute to better health conditions. Although the biogas seems to be the optimal solution to a lot of problems, a more widespread use may be hindered by financial and knowledge barriers, lack of a stable supply of feedstock, local conditions and other issues. The present study is based on survey data from rural districts in the Mekong Delta, Vietnam, and collected from two questionnaires done in 2012/13 and 2015, respectively. The data analyses of the study investigate some of the obstacles in relation to a more widespread usage of biogas and 
try to extract which factors are of importance when rural households consider investment in biogas. Several hundred households and small farmers have been intensively interviewed about all topics related to biogas, and this involves both users and non-users of biogas. The results from the study give a deeper insight into motives and behavior and may thus be useful in the design of national and local policies trying to promote the biogas option.

\section{Literature Review}

By now, the literature on the uses and possibilities of biogas in developing countries is huge, but most of the studies are dealing with the science or technical issues of implementation. There are some recent survey articles on the extent of biogas usage, a listing of all the potential benefits by applying this clean and cheap renewable energy source and with mostly a science-based approach, e.g. Abassi et al. (2012) and Alemayehu (2015). Despite all the benefits from the usage of biogas there may also be potential drawbacks due to the leakage of methane from the digesters if not properly installed and maintained, Bruun et al. (2014). The study by Surenda et al. (2014) gives an extensive explanation of the biogas applications and merits of low-cost household digesters giving both economic, environmental and health benefits. This is also addressed in Cheng et al. (2014), and there seems to be little doubt about the potential gains from using the anaerobic digestion of biomass to produce clean energy. Many developing countries have the climatic conditions for this technology, but still billions of people meet the energy needs using traditional fuels like firewood or rely on more expensive fossil-fuel sources like e.g. LPG. Thus, many of the fuels used today are either polluting or expensive, and despite this the dissemination of biogas is a slow and difficult process. According to the two before-mentioned studies, the causes for the latter are high costs of installation and lack of knowledge of how to install and maintain biogas digesters, and therefore financial and technical support may be instruments needed in the process of expanding biogas options. Also low opportunity costs of the replaced energy sources (e.g. firewood) will influence the attractiveness of biogas as demonstrated for biogas in Ethiopia, see Gwavuya et al. (2012). When it comes to the reasons behind the missing or slow introduction of biogas in developing countries, the literature is much more limited. In the recent literature, three studies can be identified where the latest is Schmidt and Dabur (2014). They investigate the diffusion of biogas in India from doing interviews involving ten experts from various positions in the value chain, but the study is focusing on large-scale biogas systems. Therefore, the results may not be applicable for small-scale digester technologies, but at least the emphasis on technological and financial support can be considered as generally good instruments for advancing the introduction of biogas. For China, knowledge and experience among biogas users are to be found in Christiansen and Heltberg (2013), who analyze data from a very large survey of households from 2009, including both users and non-users of biogas. They document the positive impacts on women's time use, economic welfare and health effects from shifting from wood fuel to biogas. The main reason for not adopting biogas was lack of labor and other inputs needed to install and operate the digester (in total $42 \%$ of the respondents). Financial restrictions and lack of space and livestock made up an equally large part of the reasons for not investing in biogas. As will be seen in the analysis below for the Vietnam data, these physical or technical restrictions are not that dominant, where the technological development in biogas digesters in recent years has made adoption easier. The study by Iqbal et al. (2013) investigates factors influencing biogas adoption in Punjab, Pakistan. A questionnaire with one hundred respondents was done and with approximately half of these being non-biogas users. The findings are that the age and education of the household head, the size of land and the number of cattle positively influence on the decision to invest in biogas. These results are also in accordance with the present study where the following parts will further explore the recent results from the data collected in the Mekong districts.

\section{Survey Data for Small-scale Usage of Biogas in Rural Districts}

The present study is based on data from two sets of surveys in the Mekong Delta done in 2012/13 and 2015, respectively. Both surveys are extensive questionnaires among small farmers and households in rural districts and include questions of both technical and socio-economic contents. The first questionnaire was done in the districts Tien Giang and Vinh Long and involved around two hundred respondents, almost equally divided into users and non-users of biogas. The second one was done in the district Soc Trang with two hundred and twenty respondents, involving only non-users of biogas. The structure and questions in both surveys were designed in accordance with the former experience acquired at the Can Tho University (CTU) from surveys on similar topics. Furthermore, to secure valid data and a large rate of response, in both cases students from the CTU collected the data by visiting all farms and households for up to one hour in each case doing an interview. The students were informed about the content of the questionnaire and the biogas technology beforehand and also instructed to obtain valid and objective answers when interviewing the respondents. Both surveys have a relatively large part of technical questions about farming and biogas, but also a whole range of social and economic topics like age, 
gender, income and other family characteristics along questions of behavior and attitudes related to the energy usage. Due to these efforts invested in getting data of reasonable quality, the results in the following analysis can be considered reliable, but it will also be evident from the results presented that still there will be missing observations for some of the variables included in the sample (i.e. no answers in spite of personal interviews).

The latter reflects the difficulties of collecting survey data in rural districts of developing countries and also explains the limited knowledge on the social and economic issues related to biogas issues investigated in the present study. The next two parts will exhibit some of the empirical findings for users and non-users of biogas, respectively, but firstly a descriptive principal component analysis (PCA) of the data has been performed and is reported in the Appendix (where a short introduction to this analysis is included along with two tables of results). For the users of biogas in Table A.1, four components are found in the data set for the Tien Giang and Vinh Long districts. The sampling adequacy (0.61) is acceptable, and there is a distinct pattern of the variables divided into four components on which they load separately, although the loading values are not that high in all cases. Opposite signs on variables in a component indicate correlation of the answers also in opposite directions. The second component (PC2) is the best one to give an economic interpretation where more income, more power consumption and higher investment costs all correlate positively and make up a common component. The other ones are not that easy to interpret, but this is also telling that answers in a survey are not that uniform and easily put into categories for standard economic interpretations. For the non-users of biogas in Table A.2, the sampling adequacy is just at the level for acceptance (0.50) even with a sample size of twice the amount of observations (199) compared to the user case. Despite of this the interpretation of the five components seems more straightforward with some relatively obvious links between the variables entering each of the principal components. For example, 'want to invest' is linked to not having enough livestock (no need for a digester), and using LPG is negatively correlated with use of firewood, but still creating a component in the data set. The PCA on both surveys is revealing the interpretational difficulties and complexity in the obtained answers from both questionnaires and therefore the next parts will present more partial results from the surveys.

\section{Benefits and Factors Influencing the Adoption of Biogas}

For biogas users the data come from two districts in the Mekong Delta and with a sample size of just above one hundred. Table 1 presents reasons for investment in biogas as well as an answer to which kind of activity the saved time - e.g. due to less time use for collection of firewood - has been allocated to. The absolute number of answers is reported in Table 1.

Table 1. Factors influencing the biogas investment decision and spending of saved time; biogas users in the Tien Giang and Vinh Long districts (2013)

\begin{tabular}{lrr}
\hline Answer & Yes & No \\
\hline Factors influencing investment & & 62 \\
Reduce diseases and smell & 41 & 77 \\
Required by local authority & 26 & 99 \\
High fuel costs & 4 & 101 \\
Reduce fertilizer costs & 2 & 15 \\
Protect local environment & 88 & 38 \\
Global environmental concerns & 65 & 102 \\
\hline Use of time savings & 1 & 4 \\
Education & 99 & 61 \\
Watch media (TV) & 42 & 91 \\
Reading newspapers & 11 & 14 \\
Social work & 89 & 58 \\
Recreation (leisure) & 40 & \\
Work & & \\
\hline
\end{tabular}

Note. Absolute number of answers from the questionnaire.

High costs of fuel and fertilizer do not seem to play a role when deciding on biogas, but it must be taken into consideration that the data here only represent farmers that have done the investment. The environmental arguments are important, and for the local environment the shift to biogas can be caused by demands from local authorities due to sanitation and externalities (smell complaints, and thus correlated to the first and second factors in the table). When asked about what time savings will be used for, education does not appear at all, but TV and recreation are highly appreciated although some time will be allocated to more work. Thus, for the farmers already having invested in a biogas digester the decision seems to be governed by requirements from outside (the local authority or neighbor complaints). There will also be benefits of the use of biogas and the main factors are exhibited in Table 2. 
Table 2. Benefits from using biogas; biogas users in the Tien Giang and Vinh Long districts (2013)

\begin{tabular}{lrr}
\hline Answer & Yes & No \\
\hline Smokeless cooking & 42 & 73 \\
Heating (quickly) & 108 & 7 \\
Tasty food & 13 & 102 \\
Easy cleaning & 51 & 64 \\
Constant watching necessary & 71 & 44 \\
\hline
\end{tabular}

Note. Absolute number of answers from the questionnaire.

Using biogas for cooking is easy and fast and obviously the main benefit according to the survey, whereas the users do not consider food becoming more tasty. Smoke, cleaning and watching are also arguments, but the share of 'yes' is less than $50 \%$. The latter result is strongly correlated with the source of energy used before shifting to biogas. Of the one hundred respondents, approximately half of these had a significant use of firewood and the other half relied more on LPG. Thus, when half of the respondents indicate less smoke and cleaning, this corresponds to all of the users of firewood having improved kitchen conditions. The factors in Table 2, except tasty food, can therefore be considered equally important for the individual users, although depending on the type of energy replaced by biogas. For the former users of LPG less smoke and fast heating will not be arguments, but the biogas will be a cheaper energy source and will also help solving waste and sanitation problems.

\section{Factors Influencing the Decision to Invest in Biogas for Non-users of Biogas}

To increase the adoption of biogas, it is important to investigate the factors and arguments that will be important for the potential users when considering investing in the technology. In this case the survey data relate to the three districts in the Mekong Delta mentioned before, and in Tables 3 and 4 the major results are summarized.

Table 3. Knowledge of the biogas technology and factors influencing the decision to invest in biogas; non-biogas users in the Soc Trang district (2015)

\begin{tabular}{lrr}
\hline Answer & Yes & No \\
\hline Know the technology & 196 & 6 \\
Trust in technology & 193 & 9 \\
Know how to install & 186 & 16 \\
Family members accept & 201 & 1 \\
Sufficient energy for cooking & 7 & 195 \\
Enough livestock (pigs) & 148 & 57 \\
Lack of subsidy & 127 & 75 \\
High investment cost & 97 & 104 \\
\hline
\end{tabular}

Note. Absolute number of answers from the questionnaire.

The most recent survey from 2015 in the Soc Trang district reveals that biogas is a well-known technology in rural areas, it is trusted and the farmers know how to install a digester. When it comes to maintenance and operating the equipment, the data from all three districts show that this is not a problem. The family members seem to have no objections to the biogas. In the Mekong Delta many of the farmhouses are rather small and thus only have few pigs; therefore for one quarter of the respondents (57) the biogas is not relevant due to this argument. They all have sufficient energy for cooking, but this will be sources like firewood, LPG, electricity, charcoal or rice husk where the biogas alternative will give either lower costs or more clean energy. The main barrier is financial where half of the respondents claim that the high investment costs are a reason for not investing, and more than half of the farmers interviewed indicate lack of subsidy as a barrier. Therefore, to further the use of biogas information and knowledge do not appear as the most needed topics to address whereas easing the financial restrictions may be a more successful action, but also more costly. Attitudes to the financial issues among the respondents are reported in more detail in Table 4 for all districts.

Table 4. Factors influencing the decision to invest in biogas; non-biogas users in the Tien Giang and Vinh Long districts (2013) and the Soc Trang district (2015)

\begin{tabular}{lcrrr}
\hline District & \multicolumn{2}{c}{ Tien Giang/Vinh Long } & \multicolumn{2}{c}{ Soc Trang } \\
Answer & Yes & No & Yes & No \\
\hline Events that will make it likely to invest: & & & & \\
Loan, 100\% & 0 & 97 & 17 & 100 \\
Loan, 50\% & 0 & 97 & 3 & 103 \\
Subsidy, 50\% & 70 & 27 & 28 & 76 \\
Subsidy, 25\% & 3 & 94 & 0 & 91 \\
\hline
\end{tabular}

Note. The questionnaires from 2013 and 2015 have identical questions in relation to whether loans or subsidies will make it likely to invest in biogas. Absolute number of answers from the questionnaires. 
For all three hundred respondents in the surveys, loan is of no interest. This reflects the lack of a financial market or structure in rural districts and also no tradition for financing projects via credit institutions. There may be access to family loans or own savings, but a loan from a financial institution does not seem attractive as the numbers clearly reveal. A subsidy seems to be a more effective instrument where a level of $50 \%$ of the investment costs will make some farmers willing to switch to biogas. Obviously, this is costly to the public funds or whoever might subsidize the biogas digesters and thus less likely to be initiated.

For the Soc Trang district, the respondents were asked whether they considered investing in biogas in the near future. A logit model for this decision with a binary outcome (yes/no) was estimated from a range of factors expected to influence this decision as presented in Table 5, where the final model was obtained after stepwise deleting insignificant variables from the estimations. Thus, several variables most likely to have an effect on the biogas investment have been tested, but only a few of these showed up with a significant contribution to explaining the investment decision.

Table 5. A logit model of factors influencing the decision to invest in biogas; non-biogas users in the Soc Trang district (2015)

Dependent variable: "Consider biogas investment in the near future" $(\mathrm{Yes}=1, \mathrm{No}=0)$

\begin{tabular}{lll}
\hline Variable & \multicolumn{2}{l}{ Parameter estimates } \\
\hline Constant & $-2.670 * * *$ & $(0.736)$ \\
Income & $0.002 * *$ & $(0.001)$ \\
Education & $0.108 * *$ & $(0.045)$ \\
Lack of subsidy & $0.610^{* *}$ & $(0.333)$ \\
Not enough livestock & $-1.164 * *$ & $(0.354)$ \\
Electricity for cooking & $0.924 *$ & $(0.551)$ \\
Participation & $0.942 * * *$ & $(0.308)$ \\
\hline Pseudo R & 0.21 & \\
Number of observations & 218 & \\
\hline
\end{tabular}

Note. The standard error of the parameter estimates in parentheses, and the level of significance indicated as $1 \%$ $(* * *), 5 \%(* *)$ and $10 \%(*)$.

In accordance with a priori expectations, the first two variables of income and education are found to influence the biogas investment positively. Income is the total household income (millions of VND) and education is the number of years of schooling for the respondent. Higher income and more education, i.e. years of schooling, are significant at the $5 \%$ level. The binary variable 'Lack of subsidy' has a value of 1 (yes) in the case of no possibility of a subsidy with the interpretation that when not receiving a subsidy this will have a negative influence on willingness to invest in biogas. The positive sign for this variable can be interpreted as those respondents willing to invest in biogas - but missing the option of a subsidy - will answer yes to 'lack of subsidy'. Hence, subsidizing biogas will increase the likelihood of investing for these respondents.

When the farmers do not have enough livestock, it is negatively influencing the biogas decision, which is quite logical. When using electricity for cooking, this variable will have a value of 1 for yes (otherwise 0 ) and a positive answer is thereby related to a higher likelihood of investing in biogas if the respondent is already using electricity. This means saving money as electricity is an expensive energy source for cooking. The last factor (participation) means that the local community is in favor of biogas and the positive sign for the variable indicates that this will influence positively on biogas investment by the respondent. The overall degree of explanation is $21 \%$ of the variation in the data which is a reasonable value taking the kind of topic into consideration. The model is quite in accordance with the former analysis of Tables 3 and 4 where financial issues like subsidies are important instruments - but also a positive local environment - for furthering the adoption of biogas.

From the model in Table 5, a graphical exposition of the influence of income levels on the probability of investing in biogas can be computed, given all the other explanatory variables are kept at their mean values. Then a partial relationship between the income levels and probability of investing can be depicted as presented in Figure 1. 


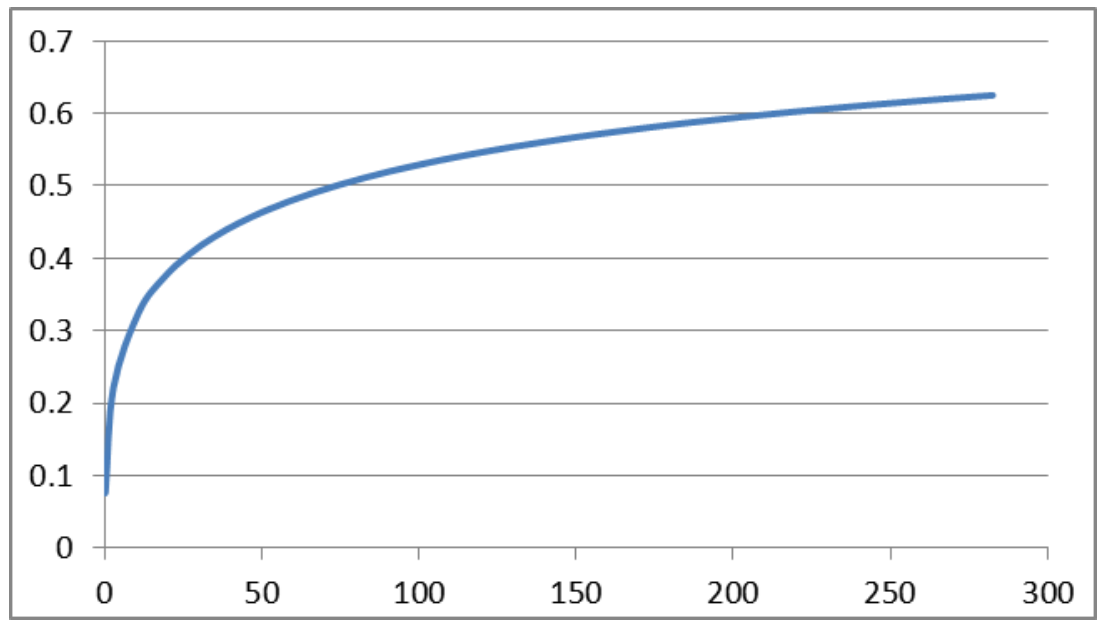

Figure 1. Probability for accepting to invest in biogas depending on the income level (Net household income, million VND annually)

Note. The probability computed from the logit model parameters in Table 5, assuming mean values for all variables, except income. The horizontal axis is net household income in million VND annually and the vertical axis is the probability to invest in biogas as a function of income.

For annual household income levels up to 50 million VND, there is a strongly increasing likelihood of investing in biogas. The level of income has to reach close to 100 million VND before the probability is more than 0.5 , and for the remaining part of the probability curve there is a more modest increase in the relationship. According to the national statistical office of Vietnam, the annual per capita level of income in the Mekong Delta was 28 million VND in 2014; probably with a lower level for the rural areas (for all rural districts in Vietnam the income was 24 million VND). Household income has to be at a relatively high level before the likelihood of investing is high, but from the numbers mentioned before not many households will have such an income level. This result is in accordance with the former findings, especially in relation to subsidies, where financial support of some kind is needed for the expansion of biogas. Small-scale biogas will probably in many cases be profitable from a private point of view as the cost of a digester is modest, but it still seems that incentives like subsidies are needed. A social cost-benefit evaluation of the biogas option might likewise show welfare gains when polluting or expensive fuels are replaced by biogas based on local resources, and therefore some kind of financial support can be justified from socio-economic arguments.

\section{Conclusion}

There is an extensive literature dealing with the use of small-scale biogas in rural areas in developing countries. A majority of the studies deal with technical topics, but also present the range of benefits when substituting from expensive or polluting energy sources like LPG or firewood to biogas based on local biomass or manure from livestock. The factors that influence the actual decisions by farmers and households on the biogas issue are less well described and explored in the literature. The present study is directed at the latter topic and based on two extensive questionnaires in three districts in the Mekong Delta. The empirical evidence from these data shows that the biogas technology is well known and accepted, and therefore these factors of information or technology should pose no problems for expanding the use of biogas. The analysis points to financial and economic factors of importance where especially the access to subsidies is likely to influence the biogas investment positively. Income and education in the rural districts are also influencing the decisions, but cannot be used as immediate instruments for promoting biogas. Thus, policy instruments to further the use of small-scale biogas will be initiatives towards creating a positive local approach to biogas, considering financial instruments like subsidies and informing about the economic savings when using biogas.

\section{Acknowledgements}

The present study based on interview data is part of the overall study of Sustainable Production of Biogas from Waste Rice Straw (www.subprom.com), which is financed by the Danish Development Agency (DANIDA). The authors wish to thank Chung Kha Linh, Vo Thi Bich Loan and Nguyen Thi Thu Trang, all students from the Can Tho University, for extensive assistance with the interviews and coding of data during the recent two years. 


\section{References}

Abassi, T., Tauseef, S. M., \& Abassi, S. A. (2012). Anaerobic digestion for global warming control and energy generation - An overview. Renewable and Sustainable Energy Reviews, 16, 3228-3242. https://doi.org/10.1016/j.rser.2012.02.046

Alemayehu, Y. A. (2015). Enhancement and Optimization Mechanisms of Biogas Production for Rural Household Energy in Developing Countries: A Review. International Journal of Renewable Energy Development, 4, 189-196. https://doi.org/10.14710/ijred.4.3.189-196

Bruun, S., Jensen, L. S. V. T. K. V., \& Sommer, S. (2014). An option for global warming mitigation or a potential climate bomb? Renewable and Sustainable Energy Reviews, 33, 736-741. https://doi.org/10.1016/j.rser.2014.02.033

Cheng, S., Li, Z. H. P., Mang, E. M., Huba, R. G., \& Wang, X. (2014). Development and application of prefabricated biogas digesters in developing countries. Renewable and Sustainable Energy Reviews, 34, 387-400. https://doi.org/10.1016/j.rser.2014.03.035

Christiansen, L., \& Heltberg, R. (2013). Greening China's rural energy: new insights on the potential of smallholder biogas. Environment and Development Economics, 19, 8-29. https://doi.org/10.1017/S1355770X13000375

Gwavuya, S. G., Abele, S., Barfuss, I., Zeller, M., \& Müller, J. (2012). Household energy economics in rural Ethiopia: A cost-benefit analysis of biogas energy. Renewable Energy, 48, 202-209. https://doi.org/10.1016/j.renene.2012.04.042

Iqbal, S., Anwar, S., Akram, W., \& Irfan, M. (2013). Factors Leading to Adoption of Biogas Technology: A Case Study of District, Faisalabad, Punjab, Pakistan. International Journal of Academic Research in Business and Social Sciences, 3, 571-578. https://doi.org/10.6007/ijarbss/v3-i11/376

Jiang, X., Sommer, S. G., \& Christensen, K. V. (2011). A review of the biogas industry in China. Energy Policy, 39, 6073-6081. https://doi.org/10.1016/j.enpol.2011.07.007

Nautiyal, S. N., Goswami, M., Manasi, S., Bez, P., Bhaskar, K., \& Khan, Y. D. I. (2015). Potential of manure based biogas to replace conventional and non-conventional fuels in India. Management of Environmental Quality: An International Journal, 26, 3-20. https://doi.org/10.1108/MEQ-04-2013-0034

Schmidt, T. S., \& Dabur, S. (2014). Explaining the diffusion of biogas in India: a new functional approach considering national borders and technology transfer. Environmental Economics Policy Studies, 16, 171-199. https://doi.org/10.1007/s10018-013-0058-6

Surenda, K. C., Takara, D., Hashimoto, A. G., \& Khanal, S. K. (2014). Biogas as a sustainable energy source for developing countries: Opportunities and challenges. Renewable and Sustainable Energy Reviews, 31, 846-859. https://doi.org/10.1016/j.rser.2013.12.015 


\section{Appendix: Principal Component Analysis of the Survey Data; Users and Non-users of Biogas}

The principal component analysis is a procedure that transforms the number of variables from the survey, which might be correlated, into a smaller number of uncorrelated variables, called principal components. The purpose is to reduce the dimension of the data set to this smaller set of principal components and at the same time retain most of the variability the data. The principal components are linear combinations of the original variables and satisfy the condition of zero covariance among the components, but maximize the variance of the linear combinations. In Tables A.1 and A.2, the principal components are in bold printing.

Table A.1. Principal components: Rotated factor pattern for selected variables representing the Tien Giang and Vinh Long districts; users of biogas

\begin{tabular}{lrrrr|r}
\hline Variable & PC1 & PC2 & PC3 & PC4 & Unexplained \\
\hline Reduce disease/smell & $\mathbf{- 0 . 5 3}$ & 0.17 & -0.18 & 0.17 & 0.39 \\
Required by local authority & $\mathbf{- 0 . 5 4}$ & -0.06 & 0.14 & -0.11 & 0.26 \\
Lack financial funds & $\mathbf{0 . 5 1}$ & 0.13 & 0.06 & 0.10 & 0.38 \\
Income & 0.10 & $\mathbf{0 . 5 9}$ & -0.02 & -0.04 & 0.28 \\
Electricity consumption & 0.04 & $\mathbf{0 . 5 8}$ & 0.00 & 0.02 & 0.36 \\
Investment costs & -0.19 & $\mathbf{0 . 5 2}$ & 0.05 & -0.03 & 0.48 \\
Reduce fertilizer expenses & 0.07 & 0.00 & $\mathbf{0 . 8 0}$ & 0.04 & 0.18 \\
Protect local environment & 0.28 & -0.01 & $\mathbf{- 0 . 4 9}$ & -0.02 & 0.42 \\
High fuel expenses & 0.11 & 0.00 & 0.15 & $\mathbf{0 . 7 5}$ & 0.28 \\
Saved time used for work & 0.17 & 0.04 & 0.18 & $\mathbf{- 0 . 6 2}$ & 0.39 \\
\hline Eigenvalue & 2.47 & 1.66 & 1.39 & 1.06 & \\
Cumulative proportion of total variance & 0.25 & 0.41 & 0.55 & 0.66 & \\
\hline Explained variance (Rho) & & & & & 0.66 \\
Sampling adequacy (KMO) & & & & & 0.61 \\
Number of observations & & & & & 99 \\
\hline Source: Da obtained from per & & & & \\
\hline
\end{tabular}

Source: Data obtained from personal interviews of households and small-scale farmers in 2013 in the Tien Giang and Vinh Long districts.

Table A.2. Principal components: Rotated factor pattern for selected variables representing the SocTrang district; non-users of biogas

\begin{tabular}{|c|c|c|c|c|c|c|}
\hline Variable & PC1 & $\mathrm{PC} 2$ & PC3 & PC4 & PC5 & Unex-plained \\
\hline Education & -0.68 & 0.06 & 0.05 & -0.09 & -0.02 & 0.34 \\
\hline Age & 0.66 & 0.12 & 0.07 & -0.06 & 0.04 & 0.40 \\
\hline Income & -0.10 & 0.43 & 0.29 & 0.22 & -0.12 & 0.47 \\
\hline Household size & 0.06 & 0.71 & -0.14 & -0.19 & 0.15 & 0.30 \\
\hline Want to invest & -0.18 & 0.15 & 0.59 & -0.04 & 0.16 & 0.39 \\
\hline Not enough livestock & -0.11 & 0.19 & -0.70 & -0.00 & 0.01 & 0.36 \\
\hline Use LPG & 0.11 & -0.13 & 0.07 & 0.71 & -0.06 & 0.30 \\
\hline Use firewood & 0.17 & -0.04 & 0.22 & -0.56 & -0.30 & 0.40 \\
\hline Electricity for cooking & 0.06 & 0.15 & 0.07 & 0.10 & 0.76 & 0.30 \\
\hline Main income rice growing & 0.05 & 0.43 & 0.03 & 0.27 & -0.52 & 0.34 \\
\hline Eigenvalue & 1.61 & 1.32 & 1.29 & 1.16 & 1.02 & \\
\hline Cumulative proportion of total variance & 0.14 & 0.27 & 0.40 & 0.53 & 0.64 & \\
\hline Explained variance (Rho) & & & & & & 0.64 \\
\hline Sampling adequacy (KMO) & & & & & & 0.51 \\
\hline Number of observations & & & & & & 198 \\
\hline
\end{tabular}

Source: Data obtained from personal interviews of households and small-scale farmers in 2015 in the Soc Trang district.

\section{Copyrights}

Copyright for this article is retained by the author(s), with first publication rights granted to the journal.

This is an open-access article distributed under the terms and conditions of the Creative Commons Attribution license (http://creativecommons.org/licenses/by/4.0/). 